\section{El desarrollo de la capacidad para leer y escribir como estrategia de enseñanza en el proceso de adquisición del español como segunda lengua ${ }^{1}$}

Rosa Esther

Delgadillo

CEPE-UNAM

\section{INTRODUCCIÓN}

A la luz de las investigaciones sobre la enseñanza-aprendizaje de la lecto-escritura en el salón de clases, nos permitimos proponer una serie de estrategias y técnicas de enseñanza basadas en el enfoque procesal, que pueden favorecer la adquisición del español como segunda lengua. En este enfoque se considera la lectura y la escritura como procesos complementarios. Para llevar a cabo esta tarea, se sugiere emplear textos descriptivos, narrativos y argumentativos, con una doble finalidad, por un lado, promover la participación activa de nuestros alumnos en la comprensión, interpretación y re-escritura de los textos propuestos y, por el otro, despertar su interés en el encuentro y la búsqueda de nuevas experiencias de lectura y escritura.

Leer y escribir son procesos que requieren de habilidades cognitivas de recepción y producción de mensajes. Ambos procesos demandan del reconocimiento de cada una de las etapas: logográfica, alfabética, ortográfica, hasta llegar al reconocimiento visual de las palabras, frases y oraciones que conforman el discurso escrito. En cada una de estas etapas se involucran, además, procesos como los de la percepción, la identificación y la comprensión de sonidos, la comprensión del significado y la interpretación del mensaje.

Ambas habilidades están íntimamente relacionadas por ser habilidades lingüísticas "que no se adquieren en contextos naturales ${ }^{2}$ sino que se aprenden con mayor o menor éxito en contextos educativos". ${ }^{3}$ Estos contextos educativos permiten al aprendiz ir conformando, primero, un mundo lingüístico diferente al suyo y, después, tener una experiencia comunicativa al usar de manera funcional, el sistema lingüístico de la lengua meta, en este caso, el español.

\footnotetext{
1 Ponencia presentada en el VI Congreso Nacional de Lingüística Aplicada en la UADY, octubre de 2001. 2 Pica distingue tres contextos de adquisición: el contexto natural, el de la enseñanza y el mixto, este último es una combinación de enseñanza en el aula y de exposición natural al ambiente de la lengua meta. T. Pica, "Adult acquisition of English as second languague under different condition of exposure", en Language learning, pp. 465-497.

3 Vega, Psicolingüística del español, p. 28.
} 
4 Widdowson, Teaching Language as Communication.

\section{PROPUESTA}

El enfoque procesal en el que basamos esta propuesta se caracteriza por focalizar su atención en el proceso de recepción, comprensión, interpretación y producción de la información proporcionada al alumno a través del input lingüístico y cultural. Hace énfasis en el proceso de composición, al centrarse en la capacidad que tiene el alumno para comprender e interpretar, y en los procesos cognitivos que emplea para llevar a cabo dichas tareas. Estos procesos los asociamos con el desarrollo de estrategias cognitivas o de aprendizaje, como lo son la generación de nuevas ideas, la formulación de objetivos, la redacción de ideas, así como su revisión y evaluación. En el asesoramiento de los alumnos, en las actividades para la composición de textos, el maestro deberá ayudarlos a que busquen ideas y a que hagan esquemas mentales con la finalidad de que puedan, más tarde, reproducir o producir textos escritos en español.

En el enfoque propuesto, consideramos que tanto la lectura como la escritura son procesos interpretativos a través de los cuales se construyen significados; es decir, que leer y escribir son principalmente habilidades lingüísticas ${ }^{4}$ con las que construimos y ampliamos nuestro conocimiento del mundo que nos rodea.

Este enfoque consta de tres partes: el objetivo del proceso de pensamiento en donde se fundamentan los componentes críticos de la estrategia, un componente metacognitivo/motivacional, y el objetivo de contenido, en el que se delinean los propósitos (de la lectura y la escritura, en este caso), se describen los pasos por seguir y se presenta un modelo de texto.

Hablar del proceso del pensamiento nos remite al tipo de estrategias (como las que se proponen más adelante) que los alumnos deberán desarrollar, o que ya han desarrollado y que ellos no se dan cuenta de cómo las emplean, o bien las que ya emplean de manera consciente.

Tradicionalmente en la comprensión se induce a que el alumno identifique: símbolos gráficos, títulos, subtítulos, dibujos, gráficas; aprecie información extralingüística, como la ubicación del emisor (autor) y del receptor (lector); haga predicciones sobre el contenido del texto; 
identifique algunos modelos sintácticos y formas morfológicas característicos del lenguaje escrito; reconozca varios tipos de textos: instructivos, descriptivos, narrativos, informativos, argumentativos, etc. Sin embargo, pensamos que lo conveniente es hacer una introducción al tipo de estrategia que se va a emplear, diciéndoles a los alumnos el porqué es útil hacer asociaciones, generalizaciones y evaluaciones, así, cuando preguntamos a cada alumno lo que hace para entender algo de lo que está leyendo, estará en posibilidad de decir cuál de estas palabras (sustantivos, adjetivos o verbos), es para él la más importante y por qué.

Con base en palabras básicas: ¿quién?, ¿qué?, ¿cuándo?, ¿para qué?, invitamos al alumno a hacer un mapa mental para que empiece a dar sentido a lo que está leyendo a partir del conocimiento previo sobre el tema y, con ello, preparándose para la escritura.

Después de una lectura global al texto o documento de trabajo, preguntar qué le dice a él ese texto (puede ser sólo un párrafo). La reconstrucción de ese texto, lo conduce a la elaboración de una paráfrasis, estrategia que también le permitirá plasmar en forma oral o por escrito sus ideas.

La ejercitación o juego en el ir y venir de las palabras a la elaboración de frases y a la combinación de oraciones le permitirá ir construyendo por escrito nuevos textos: primero serán breves párrafos, posteriormente descripciones, narraciones y breves ensayos, dependiendo del modelo de texto que se haya utilizado como input.

Trabajar con este primer componente nos remite al segundo elemento: el aspecto metacognitivo/motivacional. Esto es, cuando el alumno descubre que gracias a lo que ha hecho, ha logrado entender textos escritos en otro código lingüístico diferente al suyo, lo motiva a descubrir nuevas cosas en otros textos.

Los contenidos, tercer apartado de este enfoque, deberán estar relacionados con el tipo de objetivo que se pretenda alcanzar: lingüístico, comunicativo, discursivo o cultural. Para ello su selección deberá ser muy precisa y, por ende, deberá estar condicionada a las relaciones de cohesión y coherencia propias del texto. 
Aquí proponemos los siguientes objetivos:

1) Conocer a los estudiantes en cuanto a sus necesidades de lectura y escritura.

2) Hacer una evaluación diagnóstica de cómo escribe cada uno de los alumnos y sus conocimientos sobre formas discursivas concretas.

3) Reactivar los conocimientos previos (del mundo, gramaticales y textuales) que posee el alumno.

4) Preparar a los alumnos para la elaboración de textos.

5) Presentar a los alumnos modelos discursivos.

6) Conducir a los alumnos a la producción de textos a partir de esos modelos.

TAXONOMÍA DE ESTRATEGIAS COGNITIVAS

\begin{tabular}{|c|c|}
\hline COMPRENSIÓN & PRODUCCIÓN \\
\hline $\begin{array}{l}\text { 1) Explorar: echar una mirada al mate- } \\
\text { rial asignado para formar un mapa } \\
\text { mental o esquema. } \\
\text { 2) Acceder al conocimiento previo: } \\
\text { pensar (recordar) lo que se conoce } \\
\text { sobre el tema o mapa mental. } \\
\text { 3) Formular hipótesis o hacer predic- } \\
\text { ciones sobre el contenido del mate- } \\
\text { rial. } \\
\text { 4) Plantear objetivos: establecer moti- } \\
\text { vos para procesar la información. } \\
\text { 5) Comparar: vincular nueva infor- } \\
\text { mación con lo que se sabe, así } \\
\text { como advertir similitudes y dife- } \\
\text { rencias dentro de la nueva infor- } \\
\text { mación. } \\
\text { 6) Crear imágenes mentales: hacer } \\
\text { un cuadro mental con el fin de po- } \\
\text { der visualizar lo que se está proce- } \\
\text { sando. } \\
\text { 7) Hacer inferencias: recoger hechos } \\
\text { sobre una situación de la informa- } \\
\text { ción que se presentó y combinarlos } \\
\text { con información o creencias que ya }\end{array}$ & $\begin{array}{l}\text { 1) Acceder al conocimiento: } \\
\text { • Buscar ideas para tópicos posibles. } \\
\text { - Identificar al público. } \\
\text { - Recordar planes, modelos y otras } \\
\text { guías para redactar como la gramáti- } \\
\text { ca o estructuras textuales conocidas. } \\
\text { 2) Planificar: } \\
\text { - Recoger la información necesaria } \\
\text { recordando información impor- } \\
\text { tante y/o investigando. } \\
\text { - Organizar categorizando, delinean- } \\
\text { do, generando nuevas ideas basadas } \\
\text { en relaciones e imaginando cómo } \\
\text { se integrará la información. } \\
\text { - Planear metas de proceso y sus- } \\
\text { tanciales tales como determinar } \\
\text { el modelo de organización que se } \\
\text { usará y los puntos principales que } \\
\text { se cumplirán. } \\
\text { 3) Hacer un borrador: } \\
\text { - Centrarse inicialmente en captar } \\
\text { ideas de manera general. } \\
\text { - Pensar en el público. }\end{array}$ \\
\hline
\end{tabular}


se tienen para sacar conclusiones, tales como por qué alguien respondió de una forma particular o cómo se produjo un acontecimiento.

8) Generar preguntas y pedir aclaraciones: plantear preguntar con relación a la información presentada.

9) Seleccionar ideas importantes: identificar el problema alrededor del cual gira la acción.

10) Elaborar ejemplos, contraejemplos, analogías, comparaciones.

11) Evaluar las ideas presentadas en el material.

12) Parafrasear o resumir para representar la idea principal de toda la información (el qué).

13) Monitorear el avance/logro de los objetivos.

14) Clasificar información sobre la base de atributos.

15) Identificar relaciones y modelos: relaciones de causa/efecto, orden temporal, todo/parte, de mayor importancia/de menor importancia.

16) Organizar ideas clave.

17) Transferir o aplicar conceptos a nuevas situaciones.

18) Ensayar y estudiar.
4. Revisar:

- Evaluar y retrabajar la conclusión durante la redacción de cada borrador.

- Solicitar la opinión de los demás.

- Revisar basándose en la autoevaluación o las reacciones de los demás: organizar, aclarar y elaborar.
Tanto objetivos y contenidos deberán ayudar a que "los aprendices aprendan a hacer ellos solos aquello de lo que los profesores normalmente se ocupan en clase", como lo señala Anita Wenden. ${ }^{5}$ De esta manera, nuestros esfuerzos por ayudarles a mejorar sus habilidades lingüísticas deben completarse con un método igualmente sistemático que les ayude a desarrollar y a refinar las destrezas del aprendizaje. "El entrenamiento del aprendiz debería estar integrado, en un primer momento, por el entrenamiento lingüístico", 6 para que pueda, con facilidad, ir plasmando las ideas que va descubriendo en la lectura. Deberá, también, preguntarse para qué necesita escribir, qué tipo de documentos necesita escribir, qué elementos
5 Anita Wenden, "Learner strategies", en TESOL. Newesletter, p. 4.

6 Ibidem, p. 7. 
formales y funcionales de la lengua necesita para producir, por escrito, mensajes en español.

Para que el alumno desarrolle no sólo la capacidad de comprensión, sino también de producción se presentan el tipo de estrategias cognitivas y técnicas de enseñanza que pueden favorecer el desarrollo de esas habilidades.

Como puede observarse, en este enfoque procesal, lo relacionado con la producción o con el proceso de escribir se combinan cuatro categorías generales de estrategias: acceso al conocimiento previo, la planeación, la composición y la revisión. Cada categoría, a su vez, contiene otras estrategias que cada alumno deberá desarrollar o emplear según sus necesidades.

En el proceso de composición, el alumno deberá encontrar las palabras correctas y arreglarlas en oraciones, párrafos que le digan algo, que reflejen sus pensamientos. Para que el alumno logre esto se recomienda considerar variables de tipo contextual; de tipo sintáctico como la alteración del orden canónico de las oraciones, la anteposición de adjetivos y adverbios, el uso de las preposiciones; y el tipo discursivo al emplear marcadores que dan sentido a la variedad de textos escritos en español, según la función comunicativa que encierren: expresiva, informativo-referencial, poética, informativo-argumentativa, narrativa.

Estas variables se pueden considerar en el salón de clases empleando técnicas que permitan al profesor y al alumno reconocerlas a través de las actividades y tareas de aprendizaje.

\section{TÉCNICAS}

1. Como estrategia de enseñanza, es conveniente dar al alumno señales para leer (relacionadas, por supuesto, con las estrategias cognitivas): de anticipación, de resumen, visuales, verbales.

2. Dar al alumno una lista de textos escritos para que él decida con que frecuencia lee y escribe ese tipo de textos:

- Instructivos

- Letreros

- Cartas 
- Recados

- Noticias del periódico

7 Daniel Cassany, La cocina de la escritura, pp. 64 y 65 .

- Ensayos

- Trabajos académicos

- Cuentos

- Novelas

- Poemas

- Otros

3. Dar al alumno tareas concretas (que observe el tipo de texto, su estructura, los títulos, subtítulos y la organización en párrafos) relacionadas con las estrategias de comprensión.

4. Búsqueda de palabras clave.

5. Emplear una lluvia de ideas para que el alumno se concentre en el tema del documento o en la función comunicativa del mismo.

6. Para la exploración del tema seguimos las técnicas propuesta por Daniel Cassany: ${ }^{7}$ la de la estrella y la del cubo.

La técnica de la estrella consiste en que el alumno deberá hacerse preguntas con base en el quién, dónde, cuándo, por qué, cómo, cuántos, qué, cuál...

La técnica del cubo comprende seis caras posibles de un hecho a partir de los seis puntos de vista siguientes: descríbelo (¿cómo lo ves, sientes, tocas o saboreas?); compáralo (¿a qué se parece y en qué se diferencia?); relaciónalo (¿con qué se relaciona?); analízalo (¿cuántas partes tiene? ¿cómo funciona?); aplícalo (¿cómo se utiliza?, ¿para qué sirve?); arguméntalo (¿qué se puede decir a favor y en contra?).

7. Pedir al alumno que escriba un documento parecido al que se le mostró.

Esta última etapa es fundamental, ya que es aquí donde haremos que el alumno juegue con su proceso de composición:

$1^{\circ}$ Lo llevaremos a un trabajo de preescritura (en el que se incluyen las técnicas sugeridas: búsqueda de palabras clave y léxico básico, escritura de 1luvia de ideas).

$2^{\circ}$ El alumno deberá escribir varios borradores, mostrarlos al profesor y a sus compañeros para recibir comentarios que le permitan hacer correcciones, cuando sea necesario, a su trabajo.

$3^{\circ}$ Revisar, escribir hasta llegar a, $4^{\circ}$ La edición del trabajo. 
8 Christine G. Gordon, "Enseñanza de la estructura del cuento narrativo: un enfoque procesal de la lectura y la escritura", en K. Muth El texto narrativo. Estrategias para su comprensión, pp. 1-77.
El enfoque procesal, por ende, ofrece a los estudiantes la oportunidad de descubrir y reformular sus ideas, 1o ayuda, cada vez, a aproximarse al significado (al sentido del texto que estén escribiendo).

Este enfoque nos da la oportunidad de colocar al estudiante frente al texto en una constante interacción, ya que para que se dé la interacción entre el texto y el lector es necesario ubicar el proceso de comprensión y recuperación de los datos lingüísticos por parte del alumno. En este sentido, recordar lo escuchado o leído y presentado mediante el discurso oral o escrito, nos conduce a la reescritura. Esto es, la reescritura indica la asimilación y la reconstrucción de información textual, por parte de un lector o un oyente, y puede reflejar la comprensión. Permite estructurar respuestas según sus interpretaciones personales e individuales del texto. Es un procedimiento activo que supone la participación de los estudiantes en la reconstrucción del texto. Promueve también la integración y la personalización del contenido, ayudando a los estudiantes a ver cómo las partes del texto se interrelacionan y cómo el texto se entreteje con las propias experiencias. Por lo tanto, uno de los objetivos básicos de la re-escritura es la reconstrucción del significado del texto dentro del proceso interactivo.

Ante esta perspectiva, proponemos el empleo de la lectura y reescritura de variedad de textos, ya que puede resultar motivante a nuestros alumnos en tanto les permiten recrear su poder de imaginación, así como acceder a los saberes y valores organizados que forman parte de la cultura, con esto estaremos ayudándolos a desarrollar su creatividad a partir de técnicas como la lluvia de ideas, las analogías y la organización de todo aquello que nos dicen los textos.

Finalmente, cabe señalar que el enfoque procesal se centra tanto en el profesor (quien tiene la responsabilidad de proponer actividades, guiar y evaluar el proceso de aprendizaje de su o sus estudiantes) como en el estudiante (quien asume gradualmente la responsabilidad de su aprendizaje). En este enfoque, nos dice Christine G. Gordon: "los alumnos desarrollan un concepto de la lectura y la escritura como participación activa en el texto; el pensamiento y el comportamiento durante la lectura y la escritura se hacen explícitos. ${ }^{8}$ 
De ahí que el profesor para el diseño de las tareas, deberá partir del proceso cognitivo implícito en la etapa de la producción de mensajes escritos: desarrollo de estrategias, reflexión y práctica lingüística; por lo que los objetivos se deberán centrar, primordialmente, en:

1. la activación de los conocimientos previos (léxico, gramática, uso del español escrito y convenciones discursivas) que posee el alumno para hacer surgir sus ideas y opiniones;

2. el desarrollo de estrategias de aprendizaje;

3. la construcción de textos escritos que van desde la elaboración de párrafos sencillos, cuya finalidad es la cohesión de los elementos formales que lo constituyen, hasta la producción de textos más elaborados (memorándums, cartas, biografías, descripción y narración de eventos, diálogos y ensayos breves) cuya coherencia está determinada por su organización y su función comunicativa; y

4. la evaluación y autoevaluación de los trabajos escritos.

\section{CONCLUSIONES}

Desarrollar la capacidad para leer y escribir textos en español en un contexto socioeducativo de inmersión es conveniente considerar variables de tres tipos: de proceso, metacognitivo/motivacional y de contenido; así como el tipo de necesidades lingüísticas y comunicativas de los estudiantes.

Por otra parte, el diseño de un programa, con base en el desarrollo de la capacidad de leer y escribir de los alumnos, debe partir, como señalan Haverson y Haynes ${ }^{9}$ de cuatro categorías de estudiantes:

1) Los que no han desarrollado la habilidad de leer y escribir en su lengua materna.

2) Los que provienen de grupos socioculturales con una gran tradición en la producción escrita.

3) Los que tienen dos o tres años estudiando la lengua meta y aún no han desarrollado la capacidad para leer y escribir con fluidez y propiedad. 
4) Los que leen y escriben mucho en su lengua materna, pero que no han aprendido a hacerlo en la lengua meta por tener un sistema de escritura diferente. Tal es el caso, por ejemplo, de los alumnos asiáticos.

\section{BIBLIOGRAFÍA}

CASSANy, D., La cocina de la escritura. Barcelona, Anagrama, 1998.

-, Construir la escritura. Barcelona, Paidós,1999.

DELGADILLO, R.E., "Materiales para la producción escrita. Una propuesta metodológica", en Estudios de lingüística Aplicada. Año 18, núm. 32, diciembre, 2000. México, CELE-UNAM.

GASKINS, I y Thorne Elliot, Cómo enseñar estrategias cognitivas en la escuela. Buenos Aires, Argentina, Paidós, 1991.

GORDON, Ch., "Enseñanza de la estructura del cuento narrativo: un enfoque procesal de la lectura y la escritura", en K. Muth (comp.), E1 texto narrativo. Estrategias para su comprensión. Buenos Aires, Argentina, Aique, 1989.

HaVerson, Wave y J. Haynes, ESL/literacy for adult learners. Washington, D.C., Center for Applied Linguistics, 1982.

PICA, T., "Adult acquisition of English as a second language under different condition of exposure", en Language Learning, 1983.

Vega, M., Psicolingüística del español. Valladolid, Trotta, 1999.

WENDEN, A., "Learner strategies", en TESOL. Newsletter, núm. 19:1, pp. 4-5, 7.

Widdowson, Henry, Teaching Language as Communication. London, Oxford / New York, Oxford University Press, 1978. 